\title{
alphay ille
}

\section{Reeling Backward: The Haptics of a Medium and the Queerness of Obsolescence}

\section{Travis L. Wagner}

\begin{abstract}
This article considers the haptics of queer activist footage shot on video, and more specifically footage shot on magnetic media. Despite ideal methods of care, magnetic media faces extreme concern from a preservation standpoint. As a format that is both subject to rampant deterioration (known colloquially as "sticky shed") and obsolescence (with the ceasing VCR production), the queer activist videotape is an archival artefact irretrievably stuck in a liminal space. To play a tape is to contribute to its destruction, yet to not play the tape is to overlook potentially unique moments in queer history. As such, this article explores the very thing that is the videotape, an item latent with queer potentialities and reminders of queer failure. By approaching the ethical implications of magnetic media and the iterative nature of using magnetic media as a recording method, the article examines this format as key figure in rhetorics of queer time. Infused with archival discourses of the desire for a queer historic touch (borrowing as the title suggests from Heather Love's Feeling Backward), the article lands decidedly on the side of caution, noting that each move to save queer history chronicled on the failed format of video is to destroy the very thing it longs to embrace.
\end{abstract}

We are just as selective and biased in how we treat things as how we treat people. Obsolescence always raises moral questions about the subjects and objects that we neglect. (Peters 91)

I know very well that I cannot experience these past moments, but all the same I want to believe in the possibility of living vicariously through the video. (Hilderbrand 308)

\section{Introduction}

A camcorder zooms inward and outward on the black-rimmed red lipstick of iconic drag queen Joan Jett Blakk as she stares passively into the camera ("Blakk"). The microphone, shown moments later, picks up very little noise aside from Blakk's breathing. A few minutes pass and Blakk begins to talk, announcing herself as the official presidential candidate of Queer Nation for the 1992 election. Throughout her sardonic speech, Blakk's words become inaudible as the magnetic audio track on the Hi8 drops out. Likely due to poor recording methods, it is equally plausible that Blakk's disappearing words occur from decay and deterioration notable in this particular form of magnetic video. Blakk's own attempts to sync up her delivered speech exist at odds with the failure of the video's audio to properly sync with what is shown. This moment in queer activism, shot on a widely used video format during the height of such activist work, is partially lost. Lost not in the sense of a complete lack of the possibility of retrieval, but of a loss of its original form. 
A more sombre example comes by way of Silverlake Life: A View from Here (Peter Friedman and Tom Joslin, 1993). Posthumously chronicling the dying days of a gay couple - both diagnosed with AIDS - filmmaker Peter Friedman pieces together the home recordings of Tom Joslin and Mark Massi. During the climactic moment of the documentary viewers witness the death of Joslin while Massi, presumably holding the camera, cries off screen. As the corpse of Joslin occupies the centre of the screen, a perceptive viewer will notice black lines and moments of blurring occupying the edges of the frame. These artefacts are signs of the VHS-C on which the footage was shot, and they also signify the decay of this particularly fragile format.

Both the footage of Joan Jett Blakk's candidacy announcement and the personal video archives of Joslin and Massi reflect attempts by the queer community to chronicle their experiences through financially viable and easily distributable means. From the mid-1980s to early 2000 s the preferred recording medium for such documentation was video in its myriad formats. As Lucas Hildebrand observes, such uses of "period specific video simulates a kind of historical immediacy" (309). It was necessary for activists to chronicle their experiences in mediums available to them at the time. To watch either video is to engage in what Hildebrand labels as "retroactivism". The analogue video artefacts are part of that queer moment and indicate their place in Elizabeth Freeman's understanding of chrononormativity, wherein "like somatic facts" specific narratives become institutionalised and included within a discursive history of what it looked like to be queer (3). ACT UP, MIX NYC, Tiger TV, Queer Nation, and other queer activists took to recording video to such an extent that it is now analog(ous) with this era. As Alexandra Juhasz and Catherine Gund posit, "the overwhelming need to counter the "(mis)information about AIDS represented on broadcast television" critically "coincide[d] with the formation of a new low-end, low-tech" production format, which made available production "for those individuals and communities who never before could afford it or master it" (2). Queerness, activism, and videography are tied together temporally, appearing inextricable within an institutional understanding of queer history. These videos serve as crucial remnants of lost individuals and impassioned political activism, yet their materiality, the video itself, is subject to direct violence every single time a person encounters it in its original format.

The visual and audio markings on the queer videos discussed above are not unique to this era of footage, yet they are indicative of a larger problem for any material recorded on magnetic tape. Relying on electrical charges on magnetised strips of tape, video and audio cassettes display reconstituted information contingent on the type of electric charges recorded by the camcorder or tape recorder. Further, because the medium is magnetic in nature, such recordings are rewritable; any strip of magnetic media can, and often was, changed multiple times, irreversibly restructuring the data on the tape. Equally true is that, once something is magnetised electronically, each time a tape passes through a device (here, a tape player) it loses electrical charges and eventually returns to its original demagnetised state (Weise and Wyenand 184-6). As such, videos recorded on tapeincluding the majority of those recorded during the height of queer activism-lose information, or memory, each time one encounters them. Each playing, rewinding, and fast forwarding of such materials means that the item becomes less reflective of a temporal moment. The interviews of Joan Jett Blakk and the Joslin/Massi's home videos reflect such destruction. These moments of decay are attributes of the recorded format.

Magnetic media's primary use was the documentation of events for distribution in the moment, not long-term preservation. Accordingly, many formats of magnetic media have markedly short shelf lives, decaying to points of imperceptibility in as little as ten years after 
original use. Were this the only problem, audiovisual archivists would prioritise such formats and make digital surrogates available; however, video suffers from another equally dire challenge. In an era of digital media, video recorders and tape players are now obsolete. Each year fewer videotape recordings and viewing materials exist and what does remain is liable to break, often in the process of playing a videotape. This dual challenge of degradation and obsolescence has led audiovisual archivist Mike Casey to coin the portmanteau "degralesence" to define the unique nightmare faced by those hoping to preserve such materials (14-16). When considering this phenomenon, it becomes easy to draw uncanny parallels between the long-term failure of video and the archival discourses surrounding queerness. Obsolescence, as such, becomes an inherently queer matter.

This article explores the implications of queer archival memory as it relates to obsolescence. As the title suggests, the work borrows from Heather Love's Feeling Backward: Loss and the Politics of Queer History, extending her idea that those who "looked back" and avoided moving forward were figures who "choose to live in a present disconnected from any larger historical continuum" (8). The very nature of the decay of video tapes chronicling queer moments in history, paired with their functional obsolescence, makes such artefacts objects stuck in time looking at a moment in the past, potentially even frozen in a manoeuvre which is backward facing. Furthering Love's ideas, it is not that these documents are simply backward looking by nature, but rather that to attempt to bring them into the present (to touch them) would be to irreparably damage their contents. Playing such tapes potentially exacerbates moments of "denigration" (Love 52).

This article lays claim to the notion that video artefacts chronicling queerness are themselves queer not merely because of content, but because the very idea of obsolescence is queer. By nuancing the haptic nature of video as a moving-image format, emphasising the role nostalgia plays within queer activism/archiving, unpacking cultural notions of obsolescence, and, finally, examining the archival challenges of video preservation, this article argues that obsolete magnetic videos signify a moment of temporal impossibility for queer history. Each of these four concepts encounters an actualisation of failure in multiple instances. These are queer failures, in which damages and longings become capable of being embraced. It is no accident that queer media histor(ies) grew within such a fragile medium. It was impossible to obtain visibility within the normative rhetorics of their time of production and now their absences and near-obsolescence signify a potential desire to make that absence permanent. Queer video recordings push boundaries of best practices to their limits and challenge notions of archival advocacy for the history of queerness. More directly, the queerness of obsolescence exists within a logic that does not want to be archived. The history of queer video recordings asks not simply "can something be archived", but more emphatically, "do we have an ethical responsibility not to try?"

\section{Sticky Shed/Sticky Time: Touching Video}

In Time Binds, Elizabeth Freeman argues "that a certain literality, even materiality, gloms onto even the most rigorous deconstruction - that historical details may obstinately stick to or gum up the gears of queer theory" (112). Freeman understands queer time to be a thing wholly felt, something that when encountered as a "corporealized history" results in slippages and moments of potential "pleasure" (117). Freeman is expressly concerned with the need to feel and be felt by a queer past, to physically find a connection with something linking one to a progression through 
time, a desire to know one is not the first to tread such paths. Yet encountering such moments of connection means one is beholden to the limits and confines of the method, format and form within which the encounter takes place. If that medium is fragile, such encounters can become unforgivingly volatile.

Video tape as a form of magnetic media evokes many of the challenges and anxieties of Freeman's work. It is a medium which, when interacted with, invariably decreases functionality. To play, rewind or stop a tape is to scrape away layers, or as Freeman acknowledges, such acts cause a "dis-integration" of images with each replay (3). The shedding of layers on magnetic tape is known as "sticky shed", evoking the very concerns for lubrication and slippage so crucial to her concerns about seeking a queer pleasure in history. The gears of this format are always, to use Freeman's phrase, "gummed up" when encountered. To play any (specifically queer) footage on video is to damage it. For most items, repeated use leads to physical damage, whether that be scratches on film or creases in the binding of a book. However, for video, repeated use leads to the very thing being viewed becoming unreadable and even breaking while viewing. A video suffering from sticky shed then literalises Freeman's notion of queer histories themselves as obstinately sticky. Such decaying videos evoke Sara Ahmed's "sticky object[s]" inasmuch as they literally "pick up" the "surface [they] have traveled" (Queer Phenomenology 40). For Ahmed, this stickiness troubles one's orientation because it is a reminder of the complicated histories of queer "arrival" (40). Unlike other media forms, though, a decayed video tape cannot be repaired, nor does the information exist below markings and damage. Mucking up the gears of a video recording means that its data are no longer accessible.

If the damage associated with sticky shed were merely an issue of overuse, solving the problem would be simple. Archives would demand that people not touch such material, or wear white gloves when doing so. As Leah DeVun and Michael Jay McClure note, archives are spaces where "touch is a transgressive act" that can only happen through mediation and the mediator is often-ironically if one recalls Freeman's queer historical pleasures - a "glove" (126). Protective barriers are in place to thwart decay, but sticky shed happens regardless of protections and becomes rampant in even the most ideal storage standards (DeVun and McClure 195). There are temporary fixes to sticky shed and even potential means with which to prolong content life, however, there is no way to confirm the effects of shedding except for playing a tape. These instances of playback could mean destroying the content, no matter how loving the person's engagement with said video might be. Their actions, to borrow from Love borrowing from Foucault, might "be as much a mauling as a caress" (48). Not all decay on tape is bad, however; some decay may speak to the potentials of reuse, itself an evocatively queer mode of repetition.

Magnetic media rely upon electronic charges to shift magnetised ions, and the ability to reorganise these ions comes at a cost. While reuse is one of the major highlights of magnetic media, it also makes inevitable a tape's decreasing viability. In contrast to digital media's lossless formats, recording a video image over another one eventually provides an opportunity for images from multiple recording processes to linger, as the tape becomes less capable of holding new information. The images that reside on the tape become figures within a Derridean hauntology: figures that emerge and disappear within frames become the "presence of a specter" that is at once "insubstantial" and "haunting" (Derrida, Specters 10). The saturated bleeding of images into multiples in decaying tape is commonly referred to within audiovisual archiving as "ghosting". 
Thinking more queerly and, perhaps, more technically, the doubled and tripled bodies on a video recording become queer assemblages; or what Jasbir Puar sees as the "sensation, vibrations, echoes, speed, feedback loops, and recursive folds of feelings, coalescing through corporealities, affectivities, and multiple and contingent temporalities" (135). It is not merely that the bodies are echoing one another, but that in order for the echo to happen, both recordings had to be laid down on a worn tape. These are queer assemblage because the tape itself was subject to the sensations and temporalities of numerous recordings and now become subject to viewing by another body enfolded recursively by the queer encounter. Such duplications of imagery defy the logic of the chrononormative historical structures cited by Freeman, as multiple images compete for a single temporal space. How one encounters this temporal space is singularly, as the next time the tape is encountered the decay from playing the tape irreversibly changes its contents, perhaps even resulting in the loss of some images in their entirety.

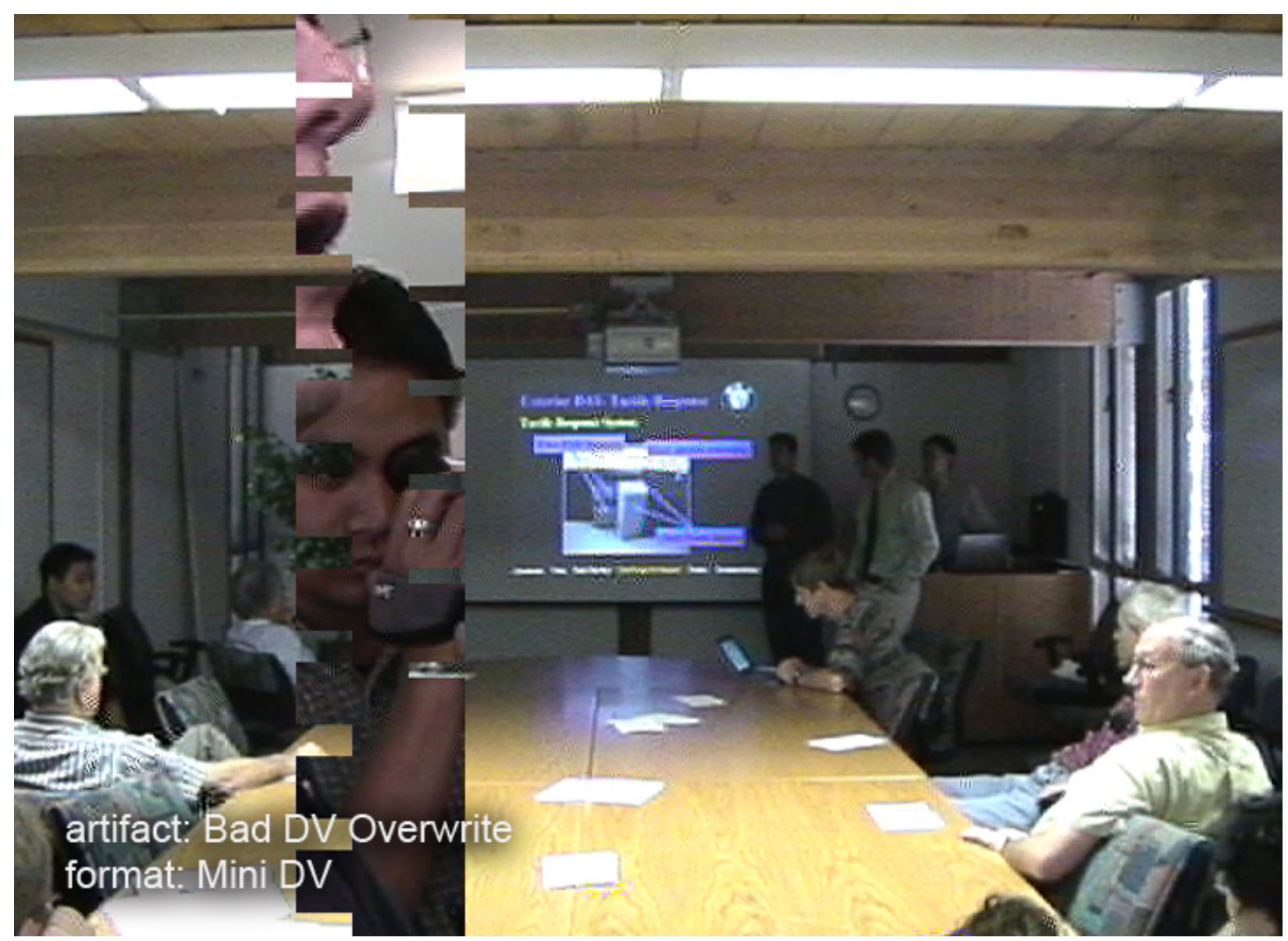

Figure 1: Two recordings at odds creating assemblages of identities. Courtesy of Audiovisual Artifact Atlas.

These queer encounters speak to both visual and haptic complications of a medium whose fragile temporalities defy chrononormative discourse. Each encounter becomes a queer movement towards decay, necessitating explorations into the way queer-oriented content situates itself within such spatiotemporal complexities. Take as a counterexample Bill Morrison's study of nitrate film erosion in the eponymously titled Decasia (2002). Here erosion is evoked as an artistic ideal, one that occurred because archives failed to properly preserve and control preventable decay. 
Tellingly, this experimental film emerged alongside the moving image archiving field's deployment of the mantra "nitrate won't wait", despite the fact the film is a century old (Slide). While nitrate film is an obsolete format, it is not queerly obsolete. The videos shot by queer activists were already out of time when they were made. These videos and the content shot on these videos never had time to wait.

\section{Nostalgic Loss/Losing Nostalgia: Identifying Historically Queer Content Shot on Video}

Lucas Hildebrand views the videotaped documentation of AIDS activism through the "lens of intergenerational nostalgia" (307). For him, the videos connect him and others who were either not alive for the AIDS crisis or who lived in regions sequestered from the epidemics to the larger queer narrative. Similarly, in discussing her own video documentary Video Remains (2005) on coping with AIDS in "Video Remains: Nostalgia, Technology, and Queer Archive Activism", Alexandra Juhasz describes historical memories of the movement as representations of a movement that generated "awful and inspiring legac[ies]" (320). Indicating assumptions about the longer-term efficacy of video, Juhasz asserts the following:

For just as nostalgia is a duration trouble, video is a duration solution, in that it allows things to last. Unlike memory or fantasy, which are personal and subjective, video is collective and objective in that it is unchanging while also being a mutually verifiable record of things that once were, are no longer, but remain present through the form of its mechanical reproduction. Video is what is left over of what visibly and audibly was in space and time. Video lasts even if we have stopped talking about what it records. When we are ready to talk about it again, it is still there even as we change and AIDS changes. Video stays the same; it shows what was. (323)

In this understanding of video documentation, Juhasz earnestly voices the belief in the infinite temporal potential of the important documentary activism of the era, which was selfdirected and communal in nature. Activists engaged in the chronicling of queer loss and subsequent grievances did so because institutions refused to acknowledge the social issue, let alone view the events as warranting chronicling. Nevertheless, the presumption that video lasts has proven false in recent years; much to the dismay of Juhasz and others, video does not stay the same. Still, video remains the prescribed choice for documentation. In the nostalgic memory of AIDS activism, video recordings remain central to the historical narrative and help theorists/activists, including Juhasz and Hildebrand, to make individualised connections to a movement. It is only recently that the way these linkages are fraught with decay and loss has become apparent. The videotapes from Juhasz's Video Remains have become just that: remains. The act of chronicling death becomes a different act when the medium itself is always moving towards destruction, and this duality warrants further reflection.

Attempting to conceptualise an understanding of the way individuals enact historical selfrepresentation, Jacques Derrida offered up the term "mal d'archive", or archive fever. Archive fever is the impulse of the person, or collective, to mark with artefacts a representation of their historical moment, while simultaneously acknowledging the impossibility of wholly representing such instances. For Derrida, the desire to document implies an awareness that the very institutions in charge of documenting have failed to do so. But further, the entity engaged in acts of archiving itself also fails. To willingly archive a moment is a hapless repetition that both "repeat[s]" and 
"recall[s]" the "instituting violence" it opposes, but because this desire posits a "memory with the anticipation of the future to come", those who choose to archive (here to videograph) moments of oppression and injustice do so fully aware of latent futilities (Derrida, Archive 79). This futility, however, manifests itself proactively in the face of failure, imploring activists and archivists to drive farther and harder to account for as many voices, narratives and faces as possible. This is evidenced brilliantly in the mass amounts of videotaped work undertaken by ACT UP, most recently highlighted within their oral history repository. Alternatively, archive fever deploys itself as a blissful ignorance, as evidenced by the presumption that video remains ever present and always able to be returned to when one is able to do so. Arguably, when Hildebrand imagines video as a moment of nostalgia to reflect upon as a nonurban queer, it is the video he envisions as a point of connection. Hildebrand wants to use videotaped activism as a space to look back onto, at once connecting himself to the history of queer activism and, simultaneously, pushing a historical narrative forward. What is imagined in these temporal and historical encounters is that the content of such videos eclipses their format.

\section{Queerly Obsolete: The Aesthetics of a Failed Format}

When such desires to encounter queer history arise in this manner, a question remains unanswered about the possibility of the encounter and, even more importantly, the implications of media destruction in such moments. For it is not simply that any given format or medium fails, but that the format ceases to be prevalent. The obsolete item is replaced by the modern, cutting edge and more temporally relevant. Queer failure provides a useful methodology to examine obsolescence, inasmuch as it represents objects and processes that move from places of prominence to more marginal and disparate spaces, demanding the rethinking of discursive functions and alternative queerly oriented potentialities. Failure, as Jack Halberstam posits, offers a chance for "alternative ways of knowing and being" which may not emerge or retain presence in "successful" discourses (24). It speaks in ways not available elsewhere, it allows narratives to potentially re-emerge or speak in the spaces not occupied by power. Failure sees its new generative potentials in the margins. Like failure, obsolescence offers a venue for queer examination, because each obsolete object marks a startling reminder of past failures, whether nostalgic or nihilistic.

Of the potentials found in obsolescence, Jennifer Gabrys argues that "obsolete technologies do not disappear into the past so much as they shore up the margins, playing silent witness to the newness of the newest devices" (115). The latent failings of obsolescence spur an awareness of what new and modern technologies should be doing, while also denoting what any respective format did not do. Such a multiplicity of meanings makes obsolete formats ripe for queer considerations, for they are a signifier of the past as failing.

In engaging with the obsolete format, an individual becomes complicit with Heather Love's antisocial queer figure, as the attempt to turn backward is met with a startlingly real encounter with the "present disconnected from any historical continuum" (8). It is not that the obsolescence was a problem in the moment of the material's creation or use, nor is it necessary that the problem of obsolescence will be one of the future (as these obsolescences will themselves become obsolete), but a problem absolutely tied to an individualised and historical encounter with a medium. Each attempt to play an obsolete video requires one to have the correct device, an understanding of how that device works, and the faith that the device functions properly. To engage with obsolete media is to be aware of the possibilities embodied in the object created and to accept that this engagement 
in the present defines what has been and will be lost. An individual encountering materials on video will likely realise that this is merely a "sliver of a sliver" of what was recorded, and further realise that more was left unpreserved (Harris 65). Obsolescence not only takes on questions of queer potentials of what might have been chronicled and wasn't, and what may still exist or have been lost, it also invites a nearly fetishistic longing to touch the remains.

To see the potential of activism chronicled on video as an escape for the nonurban queer, as Hildebrand does, suggests the specific temporality of these encounters; in this case, a temporality that allowed Hildebrand in the past to engage with his future. As he suggests throughout Retroactivism, his encounter with queer activist videos in his youth provided him hope for his future. Arguably, this encounter narrative is itself obsolete. It is not the preserved digital versions of the videos which Hildebrand longs for, but the very obsolete videos in tape players that allowed him his dream of a future, a "horizon" to look towards positively (Muñoz 1). In this way, the discussion of queer historical video remains fetishistic: its obsolescence makes it an untouchable artefact of memory, an artefact that served as inspiration for those in the movement. For some, the tapes are the media artefact which will always represent the era. Yet, untouchability only applies to the content, not the format. To long for the obsolete videos of an era riven by loss and energised by activism is to muddy the lines between what Eve Kosofsky Sedgwick sees as "materiality at the level of affect" versus actual "texture" (21): it is the difference between feeling an encounter with the obsolete and actually touching the obsolete. While the divide between touching (physical) and feeling (emotional) is hardly new to archival discourse, when it refers to video, obsolescence as a point of nostalgic longing becomes implicit in the act of touching. Mediating this encounter is, then, not part of the imagined return to what makes such materials crucial to queer historiography; instead, the repeated use of the item in its singular original form becomes absolute. Haptic uses destroy tapes, rendering nostalgia violent.

Queer recordings shot on video complicate what it means to touch history, because it is something that must be felt emotionally and bodily. One must be able to engage with the tape temporally, which means being able to pause, rewind and move through parts indefinitely. Each pass through the tape deck and prolonged pausing on the tape changes its function and its aesthetic. The types of dropout heard in Joan Jett Blakk's presidential announcement or the black spots emerging in Silverlake Life signify markings of use the same way marginalia might reveal one's ideas, yet in the context of video, it becomes inextricably associated with the historical record. When discussing not queer activist videos but instead Todd Haynes's Superstar: The Karen Carpenter Story (1988), Hildebrand observes that many individuals viewed the 16mm experimental film on shoddy dubbed videotapes of the film, making their consumption of the "original" riddled with decay and dropout. Thus, when viewers encountered a pristine version of the film print they complained, suggesting that the experience did not match the nostalgic memories they possessed regarding the film (Hildebrand 184-5). Tied to these tapes and their decay was a fetishism for not only the obsolescence, but the very markings of age and use.

In contrast to these fans, Juhasz's and Hildebrand's relationship to queer video activism is contingent on video's fallibility as a medium. Signs of failure are not dread-inducing for either. Instead, deteriorating tapes serve as warm reminders of the format, the format's obsolescence, and linkages to the future never fully achieved. Presuming that the markings of decay are indicative of both past reception and inevitable future loss, the questions of how to archive such recordings becomes profoundly complex. 


\section{Be Kind, Don't Rewind: Queering the Archival Logics of Video Preservation}

At the heart of discussions concerning the digitisation and long-term preservation of videos chronicling queer history is the problem of tragic encounter(s). As evidenced through earlier discussions, each encounter with a video tape could be the last. Theorists of archival practice offer at least two views: the first, that digitisation offers the only assured long-term preservation for any and all materials, whereas a second posits a purity to well-kept spaces for physical items without digital surrogates (Conway).

Magnetic media troubles both arguments, as deterioration occurs regardless of perfect archival safekeeping, and such deterioration is only verifiable when one attempts to play a tape. The bind for magnetic media remains uncertain on both ends: to digitise is to enact potentially irrevocable damage, whereas to ignore the tape is to let the potential for damage grow exponentially and to relinquish an engagement with the documents of queer history. If queer theory works to complicate binaries and dichotomies of all varieties, then tapes are latently queer. It is wholly possible that as archivists attempt to save the materials on a given video format they will destroy the record in the process. The tape becomes the media(ted) antisocial figure of Love's world and the attempt to transfer to a less obsolete format becomes Foucault's mauling caress. It is not so much that the act of saving material is violent here, but that such manoeuvres inevitably imply that such work will encounter or even produce instances where material cannot be saved.

It is by obsolescence that queer activist work shot on video remains its own queer figure of the past that can never fully be reclaimed. While the activists, artists, and burgeoning archivists who shot the video did so to mark the moment in history, the impetus was for accessibility and use in that moment; arguably, they were neither turning backward nor looking forward, but wholly present in that moment. Queerness in that moment was about how to "impress" a communal representation onto the space and much like the loss associated with the community from the era, the failings of an obsolete medium now require communities of queer archivists to address a long fought "refusal to recognise queer loss" within archival memories (Ahmed, Cultural Politics 161). Further, the video remains which are still salvageable are not pure, unfiltered originals; but tapes dubbed, frailing, and fractured. These decayed tapes represent the aesthetic of a movement and the intervention of the medium's specific temporalities, and preserving this means queerly confronting archival desires and practices.

Preservation standards demand high-quality digital surrogates; yet, the creation of such standards grew from stable audiovisual formats, specifically archival film negatives. Imagining how to preserve such materials emphasises finding the purest version possible and do little to acknowledge the feasibility of such standards when faced with alternative media (Meyer 1-8). Queer activist videos are not pure and by the very nature of the format they become less pure with time. As Mike Casey notes, the preservation of fragile magnetic media is a "gathering storm" waiting to strike (14); here the horizon of hope is not one with an always in the future potentiality, as Jose Esteban Muñoz might imagine, but one with impending dread. Accordingly, the notion of pure versions cannot be the standard for archiving and preserving queer video; it is, firstly, a detriment to timely preservation and, second, it is a disservice to the aesthetics of the medium on which it was shot. Video footage from queer activism looks bad, it is not preservation quality, but this cannot be the deterrent for its archival inclusion. A broken digital surrogate is better than no surrogate for future queer nostalgias to function: one must have something with which to look back onto. Holding a tape cannot be this alternative. Archiving queer video tapes requires thinking about 
archiving standards queerly. Decay can and should tell one about the nature of this type of activism; it was necessarily haphazard, chaotic, and did not always work. An objectively pure form of archival information is impossible and to demand that items within archival spaces adhere to this is to be inclusive within disingenuous, neoliberal terms. Queer materials, especially decaying videos, must be preserved on their own terms, decentralising institutional standards and accepting temporality as wonderfully adversarial on all accounts.

\section{Conclusion}

In her text on queer time and medieval literature, How Soon Is Now?, Carolyn Dinshaw separates the idea of "soon" within queer time to what it means to be in the "now" of queer time (2). Though Dinshaw's discussion has no clear ties to magnetic video tape, the discussion of the format's imminent demise reeks of soon-ness versus nowness. The ability to preserve queer memories shot on video has already failed, but such failure remains routinely ignored through an odd combination of unquestioned nostalgia and forward-looking queer memorialisation. Loss of this movement's artefacts remains too close to be felt, and no amount of either retroactive or proactive work can shift this failure. What remains to be done is an exploration of the spaces and moments wherein such memorialisation has occurred.

This paper began with examples of two works digitally preserved beyond their video format, one undertaken by activist-oriented media archivists (Media Burn's transfer of Joan Jett Blakk's speech) and the other through digital redistribution (an illegal YouTube copy of Silverlake Life). Both examples break with logics of archival digital preservation. Each item takes on a life beyond its failed medium, because of the activism of alternative archives. Both acts reflect reorientations of how one preserves obsolete memories while respatialising and retemporalising these queer moments in the process. While Dinshaw imagines the amateur in the context of reading, when it comes to the preservation of queer video, her notion of the amateur as video preservationist plays a crucial role in making queer video histories "more open" and "more multiple" (24). At a point in which queer video history is already lost, one must not remain nostalgic for what failed to remain, but instead embrace what was already saved, using this as a standpoint from which to consider potential futures and potential alternatives. To affirm this sentiment, a final archived video is offered, itself riddled with discoloration and drop out.

The video is a 1991 recording of the gay men's a cappella group The Flirtations singing the lullaby "Everything Possible". As the five singers offer up a song of hopefulness, the pink backdrop becomes oversaturated, a sign of the colour's prominence in the scene, as well as a sign of the video's decay. Here though, the transferred video looks to imagine a world where "the only measure of your words and your deeds will be the love you leave behind when you are gone" ("Gay Pride"). The digital transfer, while oversaturated, grainy, and likely no longer retrievable on its original format, becomes a way of looking at the past and thinking forward simultaneously. It is no longer an obsolete mediation sticking up the gears of an inevitable trauma of queer obsolescence; instead, this transferred video becomes the deed left behind for those, as the song suggests, seeking spirits true. Yet, crucially what changes is that now to seek these spirits is to not simultaneously destroy their ghosts. Accepting the failures of queer obsolescence and the many potentials of things already digitised asks queerness not to reel backward by rewinding old tapes for the sake of nostalgia, but instead to look around and see where others have already taken the time to hit record on/anew. It is in this now that one can begin mapping queer histories. 


\section{Acknowledgement}

The author would like to express their gratitude to Ashley Blewer, Heidi Rae Cooley, Jack Halberstam, and OK Keyes for their feedback and comments on early drafts of this paper, as well as the editors of this journal for their thoughtful commentary and edits. Finally, the author would also like to thank Ed Madden for his specific feedback which happened during his phenomenal course on Queer Temporalities during which this project took form.

\section{References}

ACTUP Oral History Project. Coordinated by Jim Hubbard and Sarah Schulman, www.actuporalhistory.org. Accessed 6 Dec. 2016.

Ahmed, Sara. The Cultural Politics of Emotion. Routledge, 2013.

---. Queer Phenomenology: Orientations, Objects, Others. Duke UP, 2006.

Casey, Mike. "Why Media Preservation Can't Wait: The Gathering Storm." IASA Journal, no. 44, Jan. 2015, pp. 14-16.

Conway, Paul. Preservation in the Digital World. The Commission on Preservation and Access, Washington, DC, 1996.

Decasia. Directed by Bill Morrison, Icarus Films, 2002.

Derrida, Jacques. Archive Fever: A Freudian Impression. Translated by Eric Prenowitz, U of Chicago P, 1996.

---. Specters of Marx: The State of the Debt, The Work of Mourning and The New International. Translated by Peggy Kamuf, Routledge, 1994.

DeVun, Leah, and Michael Jay McClure. "Archives Behaving Badly." Radical History Review, no. 120,2014 , pp. 121-30.

Dinsha, Carolyn. How Soon Is Now? Medieval Texts, Amateur Readers, and the Queerness of Time. Duke UP, 2012.

Freeman, Elizabeth. Time Binds: Queer Temporalities, Queer Histories. Duke UP, 2010.

Friedman, Peter, and Joslin, Tom, directors. Silverlake Life: The View from Here. 1993

Gabrys, Jennifer. Digital Rubbish: A Natural History of Electronics. U of Michigan P, 2011.

“Gay Pride 1991 - The Flirtations (2 of 3) - 'EverythingPossible'.” Uploaded by BettyByte, YouTube, 26 Oct. 2011, www.youtube.com/watch?v=uxdLdRmUqqI. 
Halberstam, Judith. The Queer Art of Failure. Duke UP, 2011.

Harris, Verne. "The Archival Sliver: Power, Memory, and Archives in South Africa." Archival Science. Vol. 2, no. 1-2, 2002, pp. 63-86.

Hilderbrand, Lucas. "Retroactivism." GLQ: A Journal of Lesbian and Gay Studies, vol. 12, no. 2, 2006, pp. 303-17.

“Joan Jett Blakk: Queer Nation's Candidate for President 1992.” Media Burn, filmed by Bill Statements, uploaded 17 Mar. 2015, mediaburn.org/video/joan-jet-blakk-queer-nationscandidate-for-president-1992.

Juhasz, Alexandra. "Video Remains: Nostalgia, Technology, and Queer Archive Activism." GLQ: A Journal of Lesbian and Gay Studies, vol. 12, no. 2, 2006, pp. 319-28.

Juhasz, Alexandra, and Catherine Gund. AIDS TV: Identity, Community, and Alternative Video. Duke UP, 1995.

Love, Heather. Feeling Backward: Loss and the Politics of Queer History. Harvard UP, 2009.

Muñoz, José Esteban. Cruising Utopia: The Then and There of Queer Futurity. NYU Press, 2009.

Paton, Christopher. "Preservation Re-Recording of Audio Recordings in Archives: Problems, Priorities, Technologies, and Recommendations." The American Archivist, vol. 6, no. 1, 1998, pp. 188-219.

Peters, John Durham. "Proliferation and Obsolescence of the Historical Record in the Digital Era." Cultures of Obsolescence, edited by Babbette B. Tischleder and Sarah Wasserman, Palgrave Macmillan, 2015, pp. 79-96.

Puar, Jasbir K. "Queer Times, Queer Assemblages.” Social Text, vol. 23, no. 3-4, 2005, pp. $121-$ 39.

Meyer, Mark P. "Introduction to the Restoration of Motion Picture Film." Restoration of Motion Picture Film, edited by Paul Read and Mark-Paul Meyer, Butterworth-Heinemann, 2000, pp. $1-8$.

Sedgwick, Eve Kosofsky, and Adam Frank. Touching Feeling: Affect, Pedagogy, Performativity. Duke UP, 2003.

Silverlake Life: A View from Here. Directed by Peter Friedman and Tom Joslin, PBS, 1993.

Slide, Anthony. Nitrate Won't Wait: A History of Film Preservation in the United States. McFarland, 2000.

Superstar: The Karen Carpenter Story. Directed by Todd Haynes, Iced Tea Productions, 1988.

Video Remains. Directed by Alexandra Juhasz, Pitzer College, 2005. 
Weise, Marcus, and Diana Weynand. How Video Works. Taylor \& Francis, 2007.

\section{Suggested Citation}

Wagner, Travis L. "Reeling Backward: The Haptics of a Medium and the Queerness of Obsolescence." Alphaville: Journal of Film and Screen Media, no. 16, Winter 2018, pp. 67-79. www.alphavillejournal.com/Issue16/ArticleWagner.pdf.

Travis L. Wagner is currently a doctoral student in the University of South Carolina's School of Library and Information Sciences. They also have a graduate certificate in Women's and Gender Studies from USC. Their major research area focusses on the role identity plays within information organisation, particularly around the naming and representing of potentially queer identities. Travis also works closely with South Carolina based nonprofit organisations to create costeffective strategies for digital preservation of archival content. They are also the cocreator of the Queer Cola Oral History and Digital Archive Project. 